Article

\title{
Conceptual Framework for Assessing the Sustainability of Forest Fuel Reduction Treatments and Their Adaptation to Climate Change
}

\section{Tony Prato}

Department of Agricultural and Applied Economics, University of Missouri-Columbia, 355 Wild West Dr., Eureka, MT 59917-4000, USA; E-Mail: pratoa@missouri.edu; Tel.: +1-406-890-8601

Academic Editor: Vincenzo Torretta

Received: 8 December 2014 / Accepted: 20 March 2015 / Published: 26 March 2015

\begin{abstract}
Applying fuel reduction treatments (FRTs) to forested landscapes can alleviate undesirable changes in wildfire benefits and costs due to climate change. A conceptual framework was developed for determining the preferred FRTs across planning periods, adapting FRTs to future climate change, assessing the sustainability of adaptive responses to climate change, and evaluating the validity of the two premises motivating this issue of Sustainability. The conceptual framework: (1) accounts for uncertainty about future climate change and its effects on management objectives for FRTs; (2) employs biophysical simulation and mental models to estimate the management objectives for FRTs; (3) uses fuzzy TOPSIS to determine the preferred FRTs for climate futures; (4) employs the minimax regret criterion to identify the preferred FRT for each planning period; (5) determines the best strategy for adapting FRTs to future climate change; and (6) assesses landscape sustainability when using the preferred FRTs. The framework is demonstrated with constructed examples for adapting FRTs to climate change for privately- and publicly-owned forested landscapes. Based on the conceptual framework, current knowledge does not allow determining with certainty whether managers' adaptations of FRTs to future climate change are sustainable or unsustainable due to type I and II decision errors.
\end{abstract}

Keywords: conceptual framework; sustainability; fuel reduction treatments; adaptation; climate change 


\section{Introduction}

This special issue of Sustainability addresses two issues: (1) current knowledge does not allow us to determine with certainty whether adaptive responses to climate change are sustainable; and (2) some adaptation strategies can undermine long term principles of sustainable development while others can surely contribute to social and environmental sustainability. The veracity of both statements depends on the biophysical and socioeconomic attributes of the coupled natural-human system (system for short) under consideration and whether the system manager is certain or uncertain about future climate change and its effects on the system. This paper presents a conceptual framework (i.e., abstract representations designed to guide empirical research on an issue) that managers can use to determine the preferred management alternatives for a system and adapt the system to future climate change, and which a second party can use to assess the sustainability of the system. The conceptual framework is used to evaluate the veracity of the two statements for adaptation of fuel reduction treatments (FRTs) to climate change in forested landscapes. The integrative, quantitative framework presented here differs from evaluation frameworks, such as the one developed by Jabareen [1], that apply various concepts of sustainability to a plan in a qualitative manner without integrating those concepts in a manner that allows identification of the most preferred plan.

Constructed examples are used to demonstrate how the conceptual framework can be used: (1) by a manager of a forested landscape (manager for short) to determine the preferred FRTs over time and adapt FRTs to future climate change; and (2) by a second party to assess the sustainability of preferred FRTs and adaptive responses. The constructed examples pertain to a privately-owned and managed (case 1) and publicly-owned and managed (case 2) forested landscape. Both cases assume managers are uncertain about the magnitude of future climate change and its effects on management objectives for FRTs. Although the conceptual framework is applied to fuel reduction decisions for forested landscapes, it can be used to determine the preferred FRTs within planning periods, identify the best way to adapt FRTs to climate change, and assess the sustainability of adaptive responses to climate change for other systems.

\subsection{Potential Benefits of Fuel Reduction Treatments in Forested Landscapes}

During the past few decades, managing forested landscapes in the United States has become more challenging due to dramatic increases in private property damages from wildfire and wildfire suppression costs, particularly in the wildland-urban interface. According to the National Interagency Fire Center [2], an average of 1711 residences, 1199 outbuildings, and 45 businesses are destroyed annually by wildfire. Gude et al. [3] report that wildfire destroyed 10,000 residences during the period 2000-2006 with more than 5400 structures destroyed by wildfire in 2007 alone. Average federal wildfire protection and suppression costs have risen from less than $\$ 1$ billion annually in the 1990s to $\$ 1.6$ billion during the period 2006-2014 [4].

Excluding fire from American forests for 70+ years and the slowdown in timber harvesting on western federal lands have contributed to a buildup of forest fuels resulting in larger and more intense fires than historically occurred in most forested landscapes [5,6]. Fuel reduction treatments, such as light thinning, heavy thinning, and prescribed burning, can reduce extreme wildfire behavior and wildfire damages [7]. 
Safford et al. [8] assessed the effectiveness of mechanical and prescribed fire/pile burn prescriptions in reducing fire severity and tree mortality in 12 forest fires in eastern and southern California. They concluded that with few exceptions, fire severity measures, such as bole char height, scorch and torch height, scorch and torch percentage, and tree mortality were much lower in forest stands treated for fuels than in neighboring untreated stands. Martinson et al. [9] developed a meta-analytic model to synthesize results from 19 publications that reported observed fire responses from 62 treated versus untreated contrasts in confer forests. Their final model was highly significant $(p<0.001)$ and explained $78 \%$ of the variability in reported observations of fuel treatment effectiveness, indicating that the overall mean effect of fuel treatments on fire intensity and severity is large and significant. Other researchers contend, however, that reducing the frequency of catastrophic fire with mechanical thinning alone or in combination with prescribed burning should be considered a working hypothesis [10]. Overall, FRTs appear to be an effective measure for reducing wildfire damages in the wildland-urban interface.

Climate change is expected to lengthen the wildfire season and increase the amplitude and duration of weather conditions that promote larger and more intense wildfires [11]. For example, future climate change in the western US is expected to result in more heat, less snowpack, earlier snowmelt and runoff, and more variable weather patterns than in past centuries $[2,12]$.

\section{Materials and Methods}

\subsection{Overview of Methods}

This section describes three components of the conceptual framework: (1) the decision model used to determine the preferred FRTs over time (Section 2.1.1) and adapt FRTs to future climate change (Section 2.1.2); (2) estimation of management objectives for FRTs (Section 2.2); and (3) assessment of the sustainability of the preferred FRTs selected by managers (Section 2.3). In addition, the validity of the two statements is discussed in the context of the conceptual framework (Section 2.4).

\subsubsection{Decision Model for Determining Preferred FRTs}

The decision model determines the preferred FRTs over multiple, equal-length planning periods. The decision processes included in the model are as follows. First, the manager identifies the maximum hectares that can be treated with each FRT in each planning period. Maximum hectares treated are constrained by the fuel treatment budget for each planning period.

Second, for case 1, at the beginning of each planning period, the private manager selects and implements the preferred FRT, which is the FRT that maximizes expected net return for fuel treatment (ENRT) for that planning period. Because ENRT measures the profit earned from FRTs, if any, the management objective for FRTs for case 1 is to maximize the profit earned from fuel treatment in each planning period. For case 2, at the beginning of each planning period, the public manager selects and implements the most preferred FRT for that planning period with respect to three management objectives: maximizing ENRT; minimizing expected residential property losses from wildfire (ERLW); and maximizing expected ecological benefits of fuel treatment (EEBT). The preferred FRTs for planning periods in case 2 are determined using a multiple-objective decision-making procedure. The decision model is general enough to handle other management objectives besides the ones mentioned above. 
Third, for both cases, managers select preferred FRTs for planning periods taking into account uncertainty about future climate change and its effects on management objectives for FRTs. Uncertainty about future climate change occurs because scientists that develop climate futures, such as the representative concentration pathways (RCPs) specified in the IPCC's fifth assessment report [13], are unwilling or unable to assign probabilities to those futures. In addition, managers are typically uncertain about how climate futures are likely to influence management objectives. Due to both sources of uncertainty, the preferred FRT for a planning period cannot be determined using stochastic decision-making rules that require probabilities for climate futures and the effects of climate futures on FRTs. Examples of such rules include the expected value criterion and Bayesian networks.

Fourth, the best adaptive management strategy for both cases is determined based on the preferred FRTs across planning periods.

Selecting the preferred FRT for a planning period involves two separate but related decisions: (1) determining the preferred FRT for each climate future in each planning period (first decision); and (2) identifying the best FRT across climate futures for each planning period (second decision).

For case 1, the preferred FRT for each climate future within a planning period is selected based on ENRT, which is stochastic because its determinants, such as wood prices and harvest costs, are stochastic. Therefore, the first decision for case 1 is to select the preferred FRT for each climate future at the beginning of the planning period based on the distributions of the estimated values of ENRT for that period. That decision can be made by applying the stochastic efficiency with respect to a function (SERF) criterion [13] to the distributions of the estimated values of ENRT. The dominant or preferred FRT for each climate future with the SERF criterion is the one with the highest certainty equivalent [14], which is the payoff amount a manager is willing to receive in exchange for accepting the variability in ENRT for a particular FRT. For example, the SERF criterion has been applied assuming: (1) the manager's risk aversion coefficient (RAC) is in the range $(0,0.03)$, where 0 implies the manager is risk-neutral and RAC $>0$ implies the manager is risk-averse [15]; (2) constant absolute risk aversion (i.e., the risk premium a manager is willing to pay to reduce ENRT risk does not vary with the level of ENRT); and (3) the manager's utility function is exponential in ENRT (i.e., u[ENRT·I] $=\exp [-\mathrm{RAC} \times \mathrm{ENRT}]$ ) [16]. The SERF criterion has the drawback that it requires specifying the manager's risk preferences and the form of the manager's utility function. Such specifications are usually arbitrary, which is undesirable.

Alternatively, the first decision for case 1 can be made using the minimax regret criterion (MRC). With the MRC, the preferred FRT for each climate future is the one that minimizes the average maximum loss in ENRT across those futures. The average maximum loss in ENRT with a particular FRT and climate future can be estimated by taking the difference between the expected value of the distribution of the estimated values of ENRT for that FRT with no future climate change minus the expected value of the distribution of the estimated values of ENRT for that FRT and climate future.

The second decision for case 1 involves choosing the preferred FRT across climate futures for each planning period. That decision is made by applying the MRC to the preferred FRTs for climate futures in each planning period.

The first decision for case 2 is to determine the preferred FRT for each climate future within a planning period based on three management objectives: maximizing ENRT; minimizing ERLW; and maximizing EEBT. A fuzzy logic decision model is used to make the first decision for case 2. That model uses a f, multiple-objective, decision-making rule that accounts for uncertainty. Fuzzy logic has 
been used to evaluate agricultural sustainability [17,18], ecological impacts [19,20], the behavior of environmental systems [21,22], suitability of sites as scientific natural reserves [23], the efficacy of protected areas in nature conservation [24], sustainable development [25], and ecosystem management [26,27].

Several fuzzy logic procedures can be used to make the first decision for case 2. The decision model uses the fuzzy Technique for Order Preference by Similarity of Ideal Solution, or fuzzy TOPSIS. Fuzzy TOPSIS evaluates and ranks decision alternatives based on how close (or how far away) the management objectives achieved by those alternatives are to the most (or least) desirable values of the positive (or negative) objectives [28-33]. A positive objective is one for which more of the objective is preferred and a negative objective is one for which less of the objective is preferred by the decision-maker.

General steps in the fuzzy TOPSIS procedure are as follows:

(1) Managers assign narrative descriptions known as linguistic variables to the estimated values of the objectives of FRTs under each climate future and the relative importance of the objectives. Linguistic variables can be assigned independently or collectively by managers.

(2) Fuzzy numbers are assigned to linguistic variables. For example, Chen [30] and Prato [33] assigned triangular fuzzy numbers to linguistic variables. If managers collectively assign linguistic variables, then the fuzzy numbers corresponding to the collective linguistic variables are used. If managers independently assign linguistic variables, then the fuzzy numbers corresponding to the linguistic variables chosen by individual managers are averaged to obtain collective fuzzy numbers.

(3) Fuzzy TOPSIS is used to rank FRTs for each climate future within a planning period. The preferred FRT for a climate future is the top-ranked FRT for that future.

The second decision for case 2 is to choose the preferred FRT across climate futures for each planning period using the MRC. This decision is more complicated than the second decision for case 1 because case 2 selects the preferred FRTs based on three objectives, whereas case 1 selects the preferred FRTs based on only one objective. In order to apply the MRC to the second decision for case 2, a maximum loss index (MLI) is calculated for the preferred FRT for each climate future. The MLI is an index of the expected maximum losses in the three objectives for a particular climate future. Expected maximum loss for an objective with a particular climate future is the average estimated value of the objective without future climate change minus the average estimated value of the objective with that climate future. Calculation of the MLI requires managers to assign weights to the objectives, such that the sum of the weights equals one. With the MRC, the preferred FRT for a planning period is the one that minimizes the MLI across climate futures.

\subsubsection{Decision Model for Adapting FRTs to Climate Change}

The decision model in the conceptual framework determines a manager's best strategy for adapting FRTs to climate change over planning periods by applying adaptive management (AM) [34-36] to the preferred FRTs for planning periods. AM is a form of integrated learning that acknowledges and accounts for the surprising and unpredictable nature of the outcomes of management alternatives due to uncertainty about future changes in system drivers and the effects of those drivers on management 
outcomes. Kohm and Franklin [37] state that "adaptive management is the only logical approach under the circumstances of uncertainty." The National Research Council (2004) [38] states that "adaptive management [is a decision process that] promotes flexible decision making that can be adjusted in the face of uncertainties as outcomes from management actions and other events become better understood."

Adaptive management can be either active or passive. Williams [39] defines active AM as an approach that evaluates management alternatives for reducing uncertainty about ecological processes and how management decisions influence those processes, and passive AM as an approach that focuses on resource management objectives with less emphasis on learning about the effects of management alternatives on ecological processes. Nyberg [40] and Prato [41] define active AM as a management approach that designs and conducts experiments to test hypotheses about the efficacy of management alternatives and adapts management alternatives over time when warranted based on test results, and passive AM as a management approach that does not involve experiments and hypothesis testing. For the test results from active AM to be statistically reliable, the experiments must incorporate replicated, randomized, and independent treatments and controls.

Although active AM can provide statistically reliable information about the impacts of system drivers on management alternatives, it has three limitations. First, conducting experiments on management alternatives requires major investments in research, monitoring, and modeling, which can be expensive. Second, active AM cannot be used when the impacts of management alternatives or experimental treatments cannot be evaluated independently of one another; lack of independence among treatments violates one of the prerequisites of experimental design. Third, several of the prerequisites of active AM are difficult to satisfy [41]. Passive AM does not involve experimental controls and replication or randomization of management alternatives, and, as a result, does not provide statistically reliable information about how management alternatives influence objectives. Nevertheless, passive AM is generally less expensive and easier to apply than active AM.

The decision model utilizes passive AM. Specifically, the best AM strategy for both cases is determined based on the preferred FRTs across planning periods. For example, if there are four FRTs, four planning periods, and the preferred FRTs are $\mathrm{FRT}_{3}$ for the first and second planning periods, $\mathrm{FRT}_{4}$ for the third planning period, and $\mathrm{FRT}_{1}$ for the fourth planning period, then the best passive AM strategy is to switch from $\mathrm{FRT}_{3}$ to $\mathrm{FRT}_{4}$ at the beginning of the third planning period, and switch from $\mathrm{FRT}_{4}$ to $\mathrm{FRT}_{1}$ at the beginning of the fourth planning period.

\subsection{Estimating Management Objectives}

In order for managers to determine the preferred FRTs for future planning periods, they need to estimate how various FRTs and climate futures are likely to influence ENRT, ERLW, and EEBT. The effects of FRTs on harvested timber volume under different climate futures can be simulated by inputting temperature and precipitation projections for those futures and other information into the Fire BioGeoChemical (FireBGC) model [42]. FireBGCv2 is a mechanistic, individual tree succession model that includes a spatially explicit model for fire ignition and spread, and their effects on ecosystem components [42]. The FireBGCv2 model can be used to simulate fire behavior in any forested area. Simulated harvested timber volumes for FRTs can be combined with harvest costs estimated using the 
Harvest Cost Model [43] and forecasted timber prices to estimate one or more values of ENRT for each FRT, climate future, and planning period.

Burn probabilities for residential parcels in the forested landscape for each FRT and climate future are needed to estimate ERLW. Such probabilities can be estimated by inputting changes in vegetation simulated using the FireBGC model into the FSim model [44]. Simulated burn probabilities are then combined with other information (e.g., the location of residential parcels whose burn probabilities are affected by FRTs, fuel reduction treatments used in residential parcels, real estate values, etc.) to estimate ERLW for FRTs, climate futures, and planning periods [45].

Potential increases in EEBT for various FRTs can be estimated by the extent to which FRTs reduce the departure of ecological conditions in a landscape from their historic range and variability (HRV) [46]. HRV specifies an historical envelope of possible ecological conditions that can be used as reference conditions for evaluating the ecological benefits of management prescriptions [47]. For example, if heavy thinning reduces the departure of ecological conditions in a forested landscape from its HRV more than light thinning, then EEBT is higher with heavy thinning than light thinning. The ecological variables used to measure HRV need to be specified by the manager and are likely to vary with the type of landscape being evaluated.

\subsection{Assessing Sustainability of Preferred FRTs}

While a lot has been written about sustainability and sustainable resource management, there is no consensus about how to assess the sustainability of a system. The approach used in the conceptual framework assumes that a second party (i.e., someone other than the manager of the private or public forested landscape), evaluates the sustainability of the system based on a set of sustainability conditions selected by the second party. Sustainability conditions are statements about the acceptability of the values of the criteria used to evaluate sustainability. A major difference between the manager's selection of preferred FRTs and a second party's sustainability assessment is that the manager uses estimated values of the objectives as of the beginning of the planning period whereas the second party uses observations on the values of the criteria for the planning period.

\subsubsection{Evaluating Sustainability for Single-Valued Criteria}

The form of the sustainability conditions varies depending on whether there are single- or multiple-valued criteria. This section describes sustainability conditions for single-valued criteria and the next section describes sustainability conditions for multi-valued criteria. A sustainability condition for a single-valued, positive criterion (e.g., maximizing ENRT or EEBT) is that the system is sustainable with respect to that criterion when the observed value of the criterion exceeds some minimum acceptable level. For example, suppose there is only one observation for EEBT for each FRT, planning period, and climate scenario, and $\mathrm{EEBT}_{\text {min }}$ is the minimum acceptable level chosen by the second party. The system is sustainable with respect to EEBT for all FRTs that satisfy the condition EEBT $>$ EEBT $_{\text {min }}$ and unsustainable if that condition is violated (i.e., EEBT $\leq \mathrm{EEBT}_{\min }$ ). 


\subsubsection{Evaluating Sustainability for Multi-Valued Criteria}

If the second party assesses sustainability using multivalued criteria, then multivalued sustainability conditions are used. For example, if there are multiple observations on ERLW for each planning period, then the system is sustainable with respect to ERLW for all FRTs that satisfy the condition $\operatorname{Pr}\left\{E R L W \leq E E_{L} W_{\max }\right\} \geq 1-\varphi$, where ERLW $E_{\max }$ is the maximum acceptable level of ERLW, $0 \leq \varphi \leq 1$, and $1-\varphi$ is the reliability level for the probability statement. The system is unsustainable for all FRTs that violate the condition (i.e., $\operatorname{Pr}\left\{E R L W \leq E L W_{\max }\right\}<1-\varphi$ ). The sustainability condition for ERLW incorporates a maximum acceptable value because ERLW is a negative criterion. Probability statements can be evaluated using the best-fitting probability distribution for the observed values of ERLW.

Although the single-valued sustainability condition is easier to apply than the multivalued sustainability condition, the latter accounts for variability in the values of the objectives within planning periods and affords greater flexibility in satisfying the sustainability conditions than the single-valued sustainability condition. The multivalued sustainability condition can only be used when there are multiple observations for a criterion within a planning period.

\subsubsection{Weak vs. Strong Sustainability}

The third party can assess the weak or strong sustainability of a system. A system is weakly sustainable when some, but not all, of the criteria satisfy their respective sustainability conditions. Unfortunately, there is no generally accepted rule for how many criteria need to satisfy their respective sustainability conditions before a system is declared weakly sustainable. The manager would have to establish such a rule. For example, the system is weakly sustainable if at least two-thirds of the objectives satisfy their respective sustainability conditions.

An alternative way to determine whether a system is weakly sustainable when there are multiple criteria and a single observation for each criterion is to use a composite index for the criteria and determine whether the value of the index equals or exceeds some minimum acceptable value. Weak sustainability of a system with respect to multiple criteria for which there are multiple observations can be assessed by determining whether the probability that the composite index equals or exceeds some minimum acceptable value is greater than or equal to $1-\varphi$ [48]. Use of a composite index requires that all the criteria be either positive or negative. For example, a composite index can be constructed for ENRT, ERLW, and EEBT by converting ERLW from a negative criterion to a positive criterion (ENRT and EEBT are already positive criteria) by changing the objective with respect to ERLW from minimizing ERLW to maximizing the reduction in ERLW relative to some baseline value. After this conversion, it is possible to construct a composite index for the three positive criteria (i.e., maximizing ENRT, maximizing the reduction in ERLW, and maximizing EEBT).

A system is strongly sustainable when each and every criterion satisfies its respective sustainability condition.

\subsubsection{Implications of Single- vs. Multiple-Valued Objectives}

One source of uncertainty addressed in the conceptual framework is uncertainty about the effects of climate futures on management objectives. A limitation of single-valued objectives for each planning 
period is that they do not reflect such uncertainty; a single-valued objective for a climate future implies that climate future has a deterministic or unerringly effect on the objective (i.e., the objective is not a random variable). In contrast, using a multivalued objective for a climate future implies that climate future has a random effect on the objective (i.e., the objective is a random variable).

\subsection{Assessing Validity of Statements about Adaptive Responses}

This section assesses the validity of the statements about adaptive responses to climate change. Because the statements are closely related in the context of the conceptual framework, they are combined into one question: Does current knowledge allow the second party to determine with certainty whether managers' adaptations of FRTs to future climate change are sustainable? The general answer to that question is no. The reason is that the second party can commit decision errors when assessing the sustainability of individual FRTs within planning periods that can lead to decision errors in assessing the sustainability of a manager's adaptations of FRTs to climate change over planning periods. This section discusses the implications of such decision errors for sustainability assessments.

Based on a sustainability condition for a single-valued, positive criterion, such as ENRT or EEBT, the second party would consider the landscape to be sustainable with respect to that criterion when the observed value of the criterion exceeds some minimum acceptable level. Similarly, based on the sustainability condition for a multivalued negative criterion, such as ERLW, the second party would consider the landscape to be sustainable with respect to that criterion when $\operatorname{Pr}\{$ ERLW $\leq$ ERLW $\max \} \geq 1-\varphi$. It is possible for the second party to conclude the landscape is sustainable with respect to a criterion when, in reality, it is not sustainable. This is called a type I error. Conversely, it is possible for the third party to conclude that the landscape is not sustainable with respect to a criterion when, in reality, it is sustainable. This is called a type II error.

Probabilities of type I and II errors can be calculated for multivalued objectives. Suppose the second party assesses the sustainability of a forested landscape with respect to EEBT by testing the null hypothesis $\mathrm{H}_{\mathrm{o}}: \mu_{\mathrm{EEBT}}=\mathrm{EEBT}_{\min }$ against the alternative hypothesis $\mathrm{H}_{\mathrm{a}}: \mu_{\mathrm{EEBT}}>\mathrm{EEBT}_{\min }$. The null hypothesis states that the system is not sustainable and the alternative hypothesis states that the system is sustainable with respect to EEBT. These hypotheses can be tested using the sample mean and variance of EEBT for each planning period in a one-tailed $t$-test. In order to calculate the sample mean and variance of EEBT, there needs to be multiple values for EEBT in each planning period.

The probability of a type I error is the probability that the sample mean of EEBT is greater than the critical value for the $t$-test when the population mean is $\mathrm{EEBT}_{\min }$ (i.e., the probability of rejecting the null hypothesis when it is true). That probability is the area under the distribution of EEBT when $\mu_{\mathrm{EEBT}}=\mathrm{EEBT}_{\min }$ to the right of the critical value of the sample mean for the $t$-test.

The probability of a type II error or $\beta$ is the probability that the sample mean of EEBT is less than the critical sample mean for the test when the population mean exceeds EEBT min (i.e., the probability of not rejecting the null hypothesis when it is false). Beta equals the area under the distribution of the sample mean when $\mu_{\mathrm{EEBT}}>\mathrm{EEBT}_{\min }$ to the right of the critical value of the sample mean for the $t$-test. The probability of rejecting the null hypothesis when it is false (i.e., the power of the test) equals $1-\beta$. For a true population mean greater than $\mathrm{EEBT}_{\text {min }}$, the type II error decreases (or increases) and the power of the test increases (or decreases) as the type I error increases (or decreases). 
If the second party believes that a type II error is more serious than a type I error, then a lower level of significance or $\alpha$-value should be selected for the $t$-test (e.g., $\alpha=0.10$ instead of $\alpha=0.05$ ). Conversely, if the second party believes that a type I error is more serious than a type II error, then a higher level of significance should be selected for the $t$-test (e.g., $\alpha=0.05$ instead of $\alpha=0.10$ ).

Type I and II errors have implications for second-party assessments of the sustainability of a manager's adaptive responses to climate change. The second party commits a type I error when a manager's adaptations of FRTs to climate change over planning periods are declared to be sustainable when, in reality, they are unsustainable. Conversely, the second party commits a type II error when a manager's adaptations of FRTs to climate change over planning periods are declared to be unsustainable when, in reality, they are sustainable.

Consider the implications for sustainability assessments of having the second party commit a type II error in assessing a manager's adaptations of FRTs to climate change over planning periods. For example, suppose the manager determines the preferred FRTs for four planning periods are $\mathrm{FRT}_{3}$ in periods 1 and $2, \mathrm{FRT}_{4}$ in period 3 , and $\mathrm{FRT}_{1}$ in period 4 . The best passive AM strategy for the manager is to switch from $\mathrm{FRT}_{3}$ to $\mathrm{FRT}_{4}$ at the beginning of the third planning period, and switch from $\mathrm{FRT}_{4}$ to $\mathrm{FRT}_{1}$ at the beginning of the fourth planning period. Suppose the second party commits a type II error by deciding that $\mathrm{FRT}_{3}$ is not sustainable in the second planning period when it is sustainable, and $\mathrm{FRT}_{1}$ is not sustainable in the fourth planning period when it is sustainable (i.e., two type II errors are made). Then, the second party would conclude that the manager's adaptive responses to climate change in the second and fourth planning periods are not sustainable when, in reality, they are.

In general, because the second party can commit type I and type II errors in assessing the sustainability of a manager's responses to climate change, it cannot be determined with certainty whether the way managers adapt FRTs to climate change is or is not sustainable. If the probability of a type I error is relatively low, then there is a relatively low likelihood that the second party will decide that a manager's adaptations of FRTs to climate change are sustainable when they are unsustainable. Conversely, if the probability of a type II error is relatively high, then there is a relatively high likelihood that the second party will decide that a manager's adaptations of FRTs to climate change are unsustainable when they are sustainable.

\section{Constructed Examples}

This section uses constructed examples to demonstrate how to apply the conceptual framework to cases 1 and 2. A constructed example uses hypothetical values for the parameters influencing the selection of preferred FRTs for planning periods and, hence, a manager's best adaptive management strategy for FRTs. Because the constructed examples use hypothetical parameter values, the results are not definitive in terms of any differences in the preferred FRTs across planning periods, adaptive responses to climate change, and the sustainability of FRTs between cases 1 and 2 . 


\subsection{Assumptions and Procedures for Constructed Examples}

The constructed examples are based on the following assumptions and procedures:

(1) Managers of the private and public forested landscapes select one of three FRTs for the landscape at the beginning of each of five planning periods. The three FRTs are light thinning (FRT 1 ), heavy thinning $\left(\mathrm{FRT}_{2}\right)$, and prescribed burning $\left(\mathrm{FRT}_{3}\right)$. For simplicity, only one FRT is selected per planning period.

(2) The maximum amount of land that can be treated per planning period and the biophysical attributes of the landscape are the same for the private and public landscapes. This assumption is made to avoid differences, if any, in the preferred FRTs and best adaptation strategy for the two landscapes caused by differences in the maximum amount of land that can be treated in each planning period and the biophysical attributes of the landscapes.

(3) The preferred FRT for each climate future within a planning period and the best adaptation strategy for FRTs across planning periods are determined based on the following management objectives for FRTs: (a) maximizing ENRT for the private landscape; and (b) maximizing ENRT, minimizing ERLW, and maximizing EEBT for the public landscape subject to the maximum amount of land that can be treated per planning period.

(4) ENRT, ERLW, and EEBT are random variables. At the beginning of each planning period, managers use biophysical and mental models to estimate multiple values for the management objective(s) for each FRT and climate future.

(5) Future climate change is represented by four climate futures: $\mathrm{C}_{1} ; \mathrm{C}_{2} ; \mathrm{C}_{3}$; and $\mathrm{C}_{4}$. Average annual temperature increases and annual average precipitation decreases between $\mathrm{C}_{1}$ and $\mathrm{C}_{2}, \mathrm{C}_{2}$ and $\mathrm{C}_{3}$, and $\mathrm{C}_{3}$ and $\mathrm{C}_{4}$.

(6) Managers monitor the management objectives achieved by the preferred FRTs for each planning period.

(7) The private manager's preferred FRT for a climate future and planning period is the one that maximizes ENRH.

(8) The public manager's preferred FRT for a climate future and planning period is determined by ranking the three FRTs for that climate future and planning period using fuzzy TOPSIS. The preferred FRT for a climate future and planning period is the top-ranked FRT. Application of fuzzy TOPSIS requires managers to rate the estimated values of the objectives for each FRT, climate future, and planning period and the relative importance of the objectives. Ratings are done using the linguistic variables listed in the first column of Table 1. Linguistic variables are assigned to the triangular fuzzy numbers listed in the second and third columns of Table 1.

(9) Managers determine the preferred FRT for each planning period by applying the MRC to the preferred FRTs for the four climate futures.

(10)For simplicity, the criteria used by the second party to assess the sustainability of the landscape are the same as the objectives used by managers to determine the preferred FRTs. Specifically, at the end of each planning period, a second party evaluates whether the landscape is strongly sustainable with respect to ENRT, ERLW, and EEBT using monitoring data on these criteria, minimum or maximum acceptable values of criteria, and other information and procedures. Minimum acceptable values are $\$ 800$ for ENRT and 0.7 for EEBT for all planning periods. 
Maximum acceptable value of ERLW is $\$ 3000$ for all planning periods. Reliability levels (i.e., $1-\varphi$ ) for the sustainability conditions are 0.90 for ENRT, and 0.95 for ERLW and EEBT.

(11) Managers determine the best passive strategy for adapting FRTs to climate change over planning periods based on the preferred FRTs for planning periods.

The constructed examples are described in Section 3.2 for the private landscape and Section 3.3 for the public landscape.

Table 1. Linguistic variables for rating the estimated values of multiple management objectives for fuel reduction treatments (FRTs) and the relative importance of objectives, and corresponding triangular fuzzy numbers, constructed example.

\begin{tabular}{ccc}
\hline Linguistic & \multicolumn{2}{c}{ Triangular Fuzzy Number ${ }^{\text {a for Rating }}$} \\
\hline Variable $^{\text {a }}$ & Estimated Values of Objectives & Relative \\
\hline Very low $(\mathrm{VL})$ & $(0.05,0.05,1)$ & $(0.05,0.05,0.1)$ \\
Low $(\mathrm{L})$ & $(0.05,1,3)$ & $(0.05,0.1,0.3)$ \\
Moderate $(\mathrm{M})$ & $(3,5,7)$ & $(0.3,0.5,0.7)$ \\
High $(\mathrm{H})$ & $(7,9,10)$ & $(0.7,0.8,0.9)$ \\
Very high $(\mathrm{VH})$ & $(9,10,10)$ & $(0.9,1,1)$ \\
\hline
\end{tabular}

a Adapted from Chen (2000) and Prato (2012). The first number in parentheses is the minimum value, the second number is the maximum value, and the third number is the mode of a triangular probability distribution. Triangular fuzzy numbers for the relative importance of objectives have been normalized to the interval $[0,1]$.

\subsection{Constructed Example for Private Landscape (Case 1)}

The constructed example for the private landscape illustrates how the private manager determines the preferred FRT for each climate future in the first planning period and the preferred FRTs across planning periods. Table 2 shows how the average loss in ENRT for each FRT and climate future is calculated for the first planning period. Average loss in ENRT for $\mathrm{FRT}_{j}$ and $\mathrm{C}_{i}$ is the average estimated value of ENRT without future climate change when using $\mathrm{FRT}_{j}\left(\right.$ i.e., $\mathrm{ENRT}_{j, \mathrm{w} / \mathrm{oc}}$ ) minus the average estimated value of ENRT with $\mathrm{FRT}_{\mathrm{j}}$ and $\mathrm{C}_{i}\left(i . e ., \mathrm{ENRT}_{j, \mathrm{C} i}\right) . \mathrm{ENRT}_{\mathrm{j}, \mathrm{w} / \mathrm{oc}}$ and $\mathrm{ENRT}_{j, \mathrm{Ci}}(j=1,2,3 ; i=1, \ldots, 4)$ are estimated using the procedures described in Section 2.2. The maximum loss in ENRT for $\mathrm{C}_{i}$ is the maximum of the average losses across FRTs for $C_{i}$. The maximum loss increases between $C_{1}$ and $C_{2}, C_{2}$ and $C_{3}$, and $\mathrm{C}_{3}$ and $\mathrm{C}_{4}$ because the constructed example assumes a progressively hotter and drier climate between $\mathrm{C}_{1}$ and $\mathrm{C}_{2}, \mathrm{C}_{2}$ and $\mathrm{C}_{3}$, and $\mathrm{C}_{3}$ and $\mathrm{C}_{4}$.

The preferred FRT for a planning period with the MRC is the one that minimizes the maximum loss in ENRT across the four climate futures. Based on Table 2, the minimum of the maximum losses is $\$ 1300$ with $\mathrm{FRT}_{1}$. Therefore, $\mathrm{FRT}_{1}$ is the preferred FRT for the private landscape in the first planning period. The preferred FRTs for planning periods 2 through 5 are determined in a similar manner. 
Table 2. Estimated average values of expected net return for fuel treatment (ENRT) without future climate change and with three climate futures and maximum average losses in ENRT for the private landscape, in dollars, first planning period, constructed example ${ }^{\mathrm{a}}$.

\begin{tabular}{|c|c|c|c|c|}
\hline & FRT $_{1}$ & FRT $_{2}$ & $\mathrm{FRT}_{3}$ & Maximum Average Loss \\
\hline $\mathrm{ENRT}_{\mathrm{w} / \mathrm{oc}}$ & 2200 & 2500 & 2800 & \\
\hline $\mathrm{ENRT}_{\mathrm{C} 1}$ & 900 & 1400 & 1750 & \\
\hline Average $\operatorname{Loss}_{\mathrm{C} 1}$ & 1300 & 1100 & 1050 & 1300 with $\mathrm{FRT}_{1}$ \\
\hline $\mathrm{ENRT}_{\mathrm{C} 2}$ & 825 & 1500 & 1450 & \\
\hline Average $\operatorname{Loss}_{\mathrm{C} 2}$ & 1375 & 1000 & 1350 & 1350 with $\mathrm{FRT}_{3}$ \\
\hline $\mathrm{ENRT}_{\mathrm{C} 3}$ & 2100 & 1650 & 1375 & \\
\hline Average $\operatorname{Loss}_{\mathrm{C} 3}$ & 100 & 850 & 1425 & 1425 with $\mathrm{FRT}_{3}$ \\
\hline $\mathrm{ENRT}_{\mathrm{C} 4}$ & 1200 & 1800 & 950 & \\
\hline Average $\operatorname{Loss}_{\mathrm{C} 4}$ & 1000 & 700 & 1850 & 1850 with $\mathrm{FRT}_{3}$ \\
\hline
\end{tabular}

${ }^{a} \mathrm{ENRT}_{\mathrm{w} / \mathrm{oc}}$ is ENRT without future climate change and $\mathrm{ENRT}_{\mathrm{C} i}$ is ENRT for a particular FRT with climate future $\mathrm{C}_{i}(i=1, \ldots, 4)$.

As explained in Section 2.1.2, the conceptual framework, the best passive AM strategy for FRTs across planning periods is determined by the preferred FRTs for individual planning periods. Suppose application of the MRC indicates that the preferred FRTs for the five planning periods are $\mathrm{FRT}_{1}$ in the first and second periods, $\mathrm{FRT}_{2}$ in the third and fourth periods, and $\mathrm{FRT}_{3}$ in the fifth period. Therefore, the best passive AM strategy for the private manager is to switch from $\mathrm{FRT}_{1}$ to $\mathrm{FRT}_{2}$ at the beginning of the third planning period, and switch from $\mathrm{FRT}_{2}$ to $\mathrm{FRT}_{3}$ at the beginning of the fifth planning period.

\subsection{Constructed Example for Public Landscape (Case 2)}

The constructed example for the public landscape is more complicated because FRTs are selected based on three management objectives instead of one. The preferred FRT for each planning period for the public landscape is determined using the following steps. In the first step, the public manager estimates the values of the objectives for each FRT and climate future at the beginning of the planning period using the procedures described in Section 2.2.

In the second step, the public manager rates the estimated values of the objectives for each FRT and climate future and the relative importance of the objectives using the linguistic variables given in Table 1. Hypothetical manager's linguistic ratings of the estimated values of the objectives for the three FRTs and four climate futures in the first planning period and the relative importance of the three objectives for the constructed example are given in Table 3.

In the third step, the linguistic variables in Table 3 are assigned triangular fuzzy numbers based on the scheme shown in the second and third columns of Table 1. A triangular fuzzy number is designated by $\mathrm{T}(a, b, c)$, or simply $(a, b, c)$, where $a$ is the minimum value, $b$ is the mode, and $c$ is the maximum value for a triangular probability distribution. The triangular fuzzy numbers resulting from the third step are given in Table 4. 
Table 3. Public manager's linguistic ratings of the estimated values of the management objectives for three FRTs under four climate futures, and the relative importance of objectives, first planning period, constructed example ${ }^{\mathrm{a}}$.

\begin{tabular}{|c|c|c|c|c|c|c|c|c|c|c|c|c|}
\hline \multirow{2}{*}{ Fuel Reduction Treatment } & \multicolumn{4}{|c|}{ ENRT $^{b}$} & \multicolumn{4}{|c|}{ ERLW $^{c}$} & \multicolumn{4}{|c|}{ EEBT $^{\mathrm{d}}$} \\
\hline & $\mathrm{C}_{1}$ & $\mathbf{C}_{2}$ & $\mathbf{C}_{3}$ & $\mathrm{C}_{4}$ & $\mathrm{C}_{1}$ & $\mathrm{C}_{2}$ & $\mathbf{C}_{3}$ & $\mathrm{C}_{4}$ & $\mathrm{C}_{1}$ & $\mathrm{C}_{2}$ & $\mathrm{C}_{3}$ & $\mathbf{C}_{4}$ \\
\hline $\mathrm{FRT}_{1}$ (light thinning) & $\mathrm{VL}$ & VL & $\mathrm{L}$ & $\mathrm{VH}$ & $\mathrm{M}$ & $\mathrm{H}$ & $\mathrm{H}$ & $\mathrm{H}$ & $\mathrm{M}$ & $\mathrm{M}$ & $\mathrm{L}$ & $\mathrm{M}$ \\
\hline $\mathrm{FRT}_{2}$ (heavy thinning) & M & M & $\mathrm{H}$ & $\mathrm{H}$ & M & M & $\mathrm{H}$ & $\mathrm{H}$ & M & M & M & $\mathrm{L}$ \\
\hline $\mathrm{FRT}_{3}$ (prescribed burning) & $\mathrm{M}$ & $\mathrm{H}$ & $\mathrm{L}$ & $\mathrm{M}$ & $\mathrm{M}$ & $\mathrm{M}$ & $\mathrm{H}$ & $\mathrm{M}$ & $\mathrm{M}$ & $\mathrm{H}$ & $\mathrm{H}$ & $\mathrm{M}$ \\
\hline Relative importance of objective & \multicolumn{4}{|c|}{$\mathrm{M}$} & \multicolumn{4}{|c|}{$\mathrm{VH}$} & \multicolumn{4}{|c|}{11} \\
\hline
\end{tabular}

${ }^{a} \mathrm{VL}=$ very low, $\mathrm{L}=$ low, $\mathrm{M}=$ moderate, $\mathrm{H}=$ high, and $\mathrm{VH}=$ very high. ${ }^{\mathrm{b}}$ Expected net returns from fuel treatment. ${ }^{\mathrm{c}}$ Expected residential property losses from wildfire.

${ }^{\mathrm{d}}$ Expected ecological benefits of fuel treatment.

Table 4. Triangular fuzzy numbers assigned to linguistic variables for the public manager's ratings of the estimated values of the objectives for three FRTs and four climate futures, and the relative importance of objectives, first planning period, constructed example.

\begin{tabular}{|c|c|c|c|c|c|c|c|c|c|c|c|c|}
\hline \multirow{2}{*}{$\begin{array}{c}\text { Fuel reduction } \\
\text { treatment }\end{array}$} & \multicolumn{4}{|c|}{ ENRT } & \multicolumn{4}{|c|}{ ERLW } & \multicolumn{4}{|c|}{ EEBT } \\
\hline & $\mathbf{C}_{1}$ & $\mathrm{C}_{2}$ & $\mathrm{C}_{3}$ & $\mathrm{C}_{4}$ & $\mathrm{C}_{1}$ & $\mathrm{C}_{2}$ & $\mathrm{C}_{3}$ & $\mathrm{C}_{4}$ & $\mathrm{C}_{1}$ & $\mathrm{C}_{2}$ & $\mathrm{C}_{3}$ & $\mathrm{C}_{4}$ \\
\hline $\begin{array}{c}\mathrm{F}_{3} \text { (prescribed } \\
\text { burning) }\end{array}$ & $(7,9,10)$ & $(7,9,10)$ & $(7,9,10)$ & $(7,9,10)$ & $\begin{array}{c}(3,5, \\
7)\end{array}$ & $(3,5,7)$ & $\begin{array}{c}(.05,1, \\
3)\end{array}$ & $\begin{array}{l}(.05, \\
.05,1) \\
\end{array}$ & $(3,5,7)$ & $\begin{array}{c}(7,9, \\
10)\end{array}$ & $\begin{array}{c}(7,9 \\
10)\end{array}$ & $(9,10,10)$ \\
\hline
\end{tabular}


In the fourth step, fuzzy TOPSIS is applied to the triangular fuzzy numbers in Table 4 to rank the three FRTs for each climate future. The ranking for the constructed example is shown in Table 5. The top-ranked or preferred FRT for each climate future in the first planning period is $\mathrm{FRT}_{3}$ for the $\mathrm{C}_{1}$ and $\mathrm{C}_{2}, \mathrm{FRT}_{2}$ for $\mathrm{C}_{3}$, and $\mathrm{FRT}_{1}$ for $\mathrm{C}_{4}$.

Table 5. Ranking of three FRTs and preferred FRT for each climate future based on fuzzy TOPSIS, first planning period, constructed example.

\begin{tabular}{|c|c|c|c|c|}
\hline \multirow{2}{*}{$\begin{array}{l}\text { Climate } \\
\text { Future }\end{array}$} & \multicolumn{3}{|c|}{ Ranking of FRTs } & \multirow{2}{*}{ Preferred FRT } \\
\hline & First & Second & Third & \\
\hline $\mathrm{C}_{1}$ & $\mathrm{FRT}_{3}$ & $\mathrm{FRT}_{2}$ & $\mathrm{FRT}_{1}$ & $\mathrm{FRT}_{3}$ \\
\hline $\mathrm{C}_{2}$ & $\mathrm{FRT}_{3}$ & $\mathrm{FRT}_{2}$ & $\mathrm{FRT}_{1}$ & $\mathrm{FRT}_{3}$ \\
\hline $\mathrm{C}_{3}$ & $\mathrm{FRT}_{2}$ & $\mathrm{FRT}_{3}$ & $\mathrm{FRT}_{1}$ & $\mathrm{FRT}_{2}$ \\
\hline $\mathrm{C}_{4}$ & $\mathrm{FRT}_{1}$ & $\mathrm{FRT}_{3}$ & $\mathrm{FRT}_{2}$ & $\mathrm{FRT}_{1}$ \\
\hline
\end{tabular}

In the fifth step, the preferred FRT for the first planning period is determined by applying the MRC to the maximum average losses in the three objectives with the preferred FRTs for each climate future. Because FRTs for the public landscape are evaluated using three objectives, the maximum average loss for the preferred FRT for each climate future is estimated using a MLI. The latter is a weighted average of the maximum average losses in the three objectives with the preferred FRT for each climate future. Maximum loss for each objective is determined using the procedure described in Section 3.2 for estimating the maximum loss in ENRT for the private landscape. Weights for the objectives are specified by the manager and must sum to one. Values of the MLI fall in the interval $[0,1]$. The preferred FRT for a planning period is the one that minimizes the MLI across the four climate futures.

Suppose the MLIs for the preferred FRTs for the four climate futures in the first planning period are as shown in Table 6. Applying the MRC to the MLIs in Table 6 indicates that FRT 1 minimizes the MLI across the four climate futures in the first planning period. Therefore, $\mathrm{FRT}_{1}$ is the preferred FRT for the first planning period. A similar procedure is used to determine the preferred FRTs for the four remaining planning periods. Suppose the preferred FRTs for those four remaining periods are FRT 1 in the second planning period, $\mathrm{FRT}_{3}$ in the third and fourth planning periods, and $\mathrm{FRT}_{2}$ in the fifth planning period. Based on the preferred FRTs for planning periods, the best passive AM strategy for the public landscape is to switch from $\mathrm{FRT}_{1}$ to $\mathrm{FRT}_{3}$ at the beginning of the third planning period, then switch from $\mathrm{FRT}_{3}$ to $\mathrm{FRT}_{2}$ at the beginning of the fifth planning period.

Table 6. Maximum loss indices for preferred FRTs for four climate futures, first planning period, constructed example.

\begin{tabular}{ccccc}
\hline Climate Future & $\mathbf{C}_{\mathbf{1}}$ & $\mathbf{C}_{\mathbf{2}}$ & $\mathbf{C}_{\mathbf{3}}$ & $\mathbf{C}_{\mathbf{4}}$ \\
\hline Preferred FRT & $\mathrm{FRT}_{3}$ & $\mathrm{FRT}_{3}$ & $\mathrm{FRT}_{2}$ & $\mathrm{FRT}_{1}$ \\
Maximum loss index & 48 & 52 & 65 & 45 \\
\hline
\end{tabular}

The constructed examples show that the preferred FRTs for planning periods and best passive AM strategy for the private and public landscapes are different. Specifically, the preferred FRTs are FRT 1 in the first and second periods, $\mathrm{FRT}_{2}$ in the third and fourth periods, $\mathrm{FRT}_{3}$ in the fifth period for the private 
landscape, and $\mathrm{FRT}_{1}$ in the first and second periods, $\mathrm{FRT}_{3}$ in the third and fourth planning period, and $\mathrm{FRT}_{2}$ in the fifth planning period for the public landscape. In general, the preferred FRTs for the two landscapes are likely to be different because they are determined using different objectives. However, the differences in the preferred FRTs for the private and public landscape for the constructed examples are not managerially significant because the constructed examples use hypothetical data and information.

\subsection{Assessing Sustainability for the Constructed Examples}

Based on the seventh item listed in Section 3.1, strong sustainability with respect to the three criteria requires concurrent satisfaction of the following sustainability conditions:

$$
\begin{gathered}
\mathrm{p}\{\mathrm{ENRT} \geq \$ 800\} \geq 0.90 ; \\
\mathrm{p}\{\mathrm{ERLW} \leq \$ 3000\} \geq 0.95 ; \text { and } \\
\mathrm{p}\{\mathrm{EEBT} \geq 0.7\} \geq 0.95 .
\end{gathered}
$$

In the conceptual framework, the second party uses the following three-step procedure to determine whether or not the above sustainability conditions are satisfied in each planning period. First, the maximum likelihood estimation method in the Simulation and Econometrics to Analyze Risk (Simetar) program [49] is used to fit several probability distributions to the observed values of each objective for a planning period. Second, the CDFDEV function in Simetar is used to determine the best-fitting probability distribution for each objective. Third, the best-fitting probability distribution for an objective is used to determine whether or not the sustainability condition for that objective is satisfied or violated for each planning period.

For each planning period, there are four mutually exclusive outcomes for the strong sustainability assessment: (1) the preferred FRTs for the private and public landscapes are not strongly sustainable; (2) the preferred FRT for the private landscape is strongly sustainable, but the preferred FRT for the public landscape is not strongly sustainable; (3) the preferred FRT for the private landscape is not strongly sustainable, but the preferred FRT for the public landscape is strongly sustainable; or (4) the preferred FRTs for the private and public landscapes are strongly sustainable. If the preferred FRTs for all planning periods are strongly sustainable, then the best passive adaptive management strategy is likewise strongly sustainable provided the probability of type II decision errors is relatively small.

\section{Discussion}

The conceptual framework described here can be used by managers of privately- and publicly-owned forested landscapes to determine the preferred FRT for each planning period and the best strategy for passively adapting FRTs to future climate change across planning periods. In addition, a second party (i.e., someone other than the private or public manager) can use the framework to assess the sustainability of a forested landscape with respect to a set of criteria. The conceptual framework is general enough to be applied to other landscape management decisions besides the selection and adaptive management of FRTs for forested landscapes. 
The conceptual framework is admittedly complex, especially when FRTs are evaluated using multiple objectives, those objectives are multivalued in each planning period, and biophysical simulation models are used to estimate the values of the objectives. Most forest managers do not have the skills required to apply the framework in the manner described here. Managers have several options for alleviating this limitation of the framework. Two options are described below.

First, managers can select fewer management objectives and/or management objectives that are easier to estimate. For example, instead of selecting FRTs based on maximizing ENRT, minimizing ERLW, and maximizing EBBF, public forest managers can select FRTs based on minimizing the cost of achieving target levels of fuel reduction in each planning period (minimum cost target objective for short), and maximizing EEBF. The values of the minimum cost target objective are easier to estimate than the values of ENRT and ERLW because it is not necessary to apply complex fire behavior models such as FireBGC and FSim. Even for this option, future climate change needs to be considered in determining the preferred FRTs for planning periods because future climate change is expected to increase the incidence of large and intense wildfires and hence the target levels of fuel reduction needed to reduce the likelihood and consequences of future wildfires.

It is relatively easy for the manager to apply fuzzy TOPSIS to the minimum cost target and EEBF objectives, or, for that matter, the original three objectives, using a fuzzy TOPSIS spreadsheet developed by the author. The spreadsheet requires the user to enter the raw values of the estimated values of the objectives for each FRT and climate future, and specify the linguistic variables assigned to specific ranges of the raw values of the estimated objectives (e.g., the estimated normalized value of EEBT is considered very low if it falls in the range $(0,0.2)$, etc.). The spreadsheet automatically assigns linguistic variables to the raw values of the objectives based on the linguistic variables assigned to different value ranges of the objectives, assigns triangular fuzzy numbers to the linguistic ratings of the values of the objectives and the relative importance of the objectives, ranks the preferred FRTs for each climate future within a planning period, and applies the MRC to determine the preferred FRT across climate futures within each planning period. In order to apply the MRC to the preferred FRTs for climate futures within a planning period, it is necessary to construct a MLI for the two objectives. This is relatively simple once the values of the two objectives for FRTs without future climate change and with each climate future have been estimated.

The second option is relevant for a public forest manager who wants to determine preferred FRTs across planning periods based on maximizing ENRT and EEBT, and minimizing ERLW, or another complex set of objectives. Estimating these three objectives for each FRT, climate future, and planning period requires running the FireBGC and FSim models, or similar fire behavior models. Due to the complexity of these models, a manager that chooses this option would most likely have to receive assistance from a scientist experienced in running fire behavior models.

\section{Conclusions}

Future climate change is expected to increase the size and intensity of wildfires. Forest managers may be able to alleviate the growth in expected residential damages from wildfire and/or increase expected net returns and ecological benefits by applying FRTs. To achieve this goal, managers require a conceptual framework that allows them to select FRTs and adaptively manage them for climate change when there 
is uncertainty about the extent of future climate change and its effects on management objectives for FRTs. Until now, there has not been a conceptual framework that managers can use for this purpose. This paper presents such a framework and uses it to evaluate the validity of the statements regarding the sustainability of adaptive responses to climate change addressed in this special issue of Sustainability.

The conceptual framework: (1) incorporates procedures for selecting FRTs and adapting FRTs to future climate change for privately- and publicly-owned forested landscapes when there is uncertainty about future climate change and its effects on management objectives for FRTs; (2) allows management objectives for FRTs to have single or multiple values; (3) employs biophysical simulation and mental models to estimate the values of the management objectives for FRTs for different climate futures and planning periods; (4) uses fuzzy TOPSIS to determine the preferred FRT for each climate future within planning periods when there are multiple management objectives for FRTs; (5) determines the preferred FRT for each planning period by applying the MRC to the preferred FRTs for each climate future; (6) identifies the best strategy for passively adapting FRTs to future climate change based on the preferred FRTs for planning periods; and (7) allows a second party to assess whether a forested landscape is weakly or strongly sustainable using sustainability conditions for either single- or multiple-valued criteria. Application of the conceptual framework is illustrated using constructed examples.

This special issue of Sustainability is motivated by two statements: (1) current knowledge does not allow us to determine with certainty whether adaptive responses to climate change are sustainable; and (2) some adaptation strategies can undermine long term principles of sustainable development while others can surely contribute to social and environmental sustainability. The veracity of these statements for forested landscapes was evaluated using the conceptual framework by combining the two statements into a single question: Does current knowledge allow the second party to determine with certainty whether managers' adaptations of FRTs to future climate change are sustainable? The answer to that question is no. The reason for a negative answer is that the way the conceptual framework handles uncertainty about future climate change and its effects on management objectives for FRTs makes it possible for the second party to commit a type I or type II error when assessing the sustainability of a manager's selection of FRTs within planning periods and adaptations of FRTs to climate change over planning periods. A type I error (or type II error) occurs when the second party decides a forested landscape is sustainable (or not sustainable) with respect to one or more criteria, either within or across planning periods, when, in fact, the landscape is not sustainable (or is sustainable). Because probabilities of type I and type II errors are likely to exceed zero, the conceptual framework suggests it is not possible for the second party to determine with certainty whether or not a manager's selection of FRTs within planning periods and adaptations of FRTs to climate change over planning periods are sustainable.

\section{Acknowledgments}

The research reported here was supported by the National Science Foundation, Award ID 0903562.

\section{Conflicts of Interest}

The author declares no conflict of interest. 


\section{References}

1. Jabareen, Y. An assessment framework for cities coping with climate change: The case of New York City and its PlaNYC 2030. Sustainability 2014, 6, 5898-5919.

2. National Interagency Fire Center (NIFC). Wildland Fire Summary Statistics Annual Report, 2011. Available online: http://www.predictiveservices.nifc.gov/intelligence/2011_statssumm/intro_ summary.pdf (accessed on 23 March 2015).

3. Gude, P.; Rasker, R.; Noort, J. Potential for future development on fire-prone lands. J. For. 2008, 106, 198-205.

4. Gorte, R.W. Federal Funding for Wildfire Control and Management; Congressional Research Service Report for Congress: Washington, DC, USA, 2010.

5. Arno, S.F.; Allison-Bunnel, S. Flames in Our Forest: Disaster or Renewal? Island Press: Washington, DC, USA, 2002.

6. US Department of Agriculture; US Department of the Interior (USDA and USDI). Quadrennial Fire Review 2009: Final Report, 2009. Available online: http://www.nifc.gov/PUBLICATIONS/ QFR/QFR2009Final.pdf (accessed on 23 March 2015).

7. Omi, P.N.; Martinson, E.J. Effects of Fuels Treatment on Wildfire Severity; Final Report Submitted to the Joint Fire Science Program Governing Board; Colorado State University and Western Forest Fire Research Center: Fort Collins, CO, USA, 2002.

8. Safford, H.D.; Stevens, J.T.; Merriam, K.; Meyer, M.D.; Latimer, A.M. Fuel treatment effectiveness in California yellow pine and mixed conifer forests. For. Ecol. Manag. 2012, 274, 17-28.

9. Martinson, E.J.; Omi, P.N. Fuel Treatments and Fire Severity: A Meta-Analysis; Research Paper RMRS-RP-103WWW; USDA Forest Service, Rocky Mountain Research Station: Fort Collins, CO, USA, 2013; p. 38.

10. Carey, H.; Schumann, M. Modifying Wildfire Behavior-The Effectiveness of Fuel Treatments, The Status of Our Knowledge. Available online: http:/www.orww.org/Wildfires/References/ Forest_Fuels/Carey_\&_Schuman_2003.pdf(accessed on 23 March 2015).

11. Westerling, A.L.; Bryant, B.P.; Preisler, H.K.; Holmes, T.P., Hidalgo, H.G.; Das, T.; Shrestha, S.R. Climate change and growth scenarios for California wildfire. Clim. Chang. 2011, 109, 445-463.

12. Barnett, T.P.; Pierce, D.W.; Hidalgo, H.G.; Bonfils, C.; Santer, B.D.; Das, T.; Bala, G.; Wood, A.W.; Nozawa, T.; Mirin, A.A.; et al. Human-induced changes in the hydrology of the Western United States. Science 2008, 319, 1080-1083.

13. Intergovernmental Panel on Climate Change (IPCC). Fifth Assessment Report (AR5), 2014. Available online: http://ipcc.ch/report/ar5/ (accessed on 23 March 2015).

14. Hardaker, J.B.; Richardson, J.W.; Lien, G.; Schumann, K.D. Stochastic efficiency analysis with risk aversion bounds: A simplified approach. Aust. J. Agric. Resour. Econ. 2004, 48, 253-270.

15. Anderson, J.R.; Dillon, J.L. Risk Analysis in Dryland Farming Systems; Farm Systems Management Series No. 2; Food and Agriculture Organization: Rome, Italy, 1992.

16. Prato, T.; Qiu, Z.; Pederson, G.; Fagre, D.; Bengtson, L.; Williams, J. Potential economic benefits of adapting agricultural production systems to future climate change. Environ. Manag. 2010, 45, $577-589$. 
17. Dunn, E.; Keller, J.; Marks, L. Fuzzy multiple attribute decision making (MADM): A tool for agricultural and resource economics. In Proceedings of the American Agricultural Economics Association 1996 Meeting, San Antonio, TX, USA, July 1996.

18. Dunn, E.G.; Keller, J.M.; Marks, L.A. Integrated decision making for sustainability: A fuzzy MADM model for agriculture. In Multiple Objective Decision Making for Land, Water, and Environmental Management; El-Swaify, S., Yakowitz, D., Eds.; St. Lucie Press: Boca Raton, FL, USA, 1998; pp. 313-322.

19. Silvert, W. Ecological impact classification with fuzzy sets. Ecol. Model. 1997, 96, 1-10.

20. Silvert, W. Fuzzy indices of environmental conditions. Ecol. Model. 2000, 130, 111-119.

21. Metternicht, G. Assessing temporal and spatial changes of salinity using fuzzy logic, remote sensing and GIS. Foundations of an expert system. Ecol. Model. 2001, 144, 163-179.

22. Salles, P.; Bredeweg, B. Modelling population dynamics with qualitative reasoning. Ecol. Model. 2006, 195, 114-128.

23. Stoms, D.M.; McDonald, J.M.; Davis, F.W. Fuzzy assessment of land suitability for scientific research reserves. Environ. Manag. 2002, 29, 545-558.

24. Lu, Y.; Chen, L.; Fu, B.; Liu, S. A framework for evaluating the effectiveness of protected areas: The case of Wolong Biosphere Reserve. Landsc. Urban Plan. 2003, 63, 213-223.

25. Andriantiatsaholiniaina, L.A.; Kouikoglou, V.S.; Phillis, Y.A. Evaluating strategies for sustainable development: Fuzzy logic reasoning and sensitivity analysis. Ecol. Econ. 2004, 48, 149-172.

26. Prato, T. Bayesian adaptive management of ecosystems. Ecol. Model. 2005, 183, 147-156.

27. Prato, T. Assessing ecosystem sustainability and management using fuzzy logic. Ecol. Econ. 2007, 61, 171-177.

28. Hwang, C.L.; Yoon, K. Multiple Attribute Decision Making; Lecture Notes in Economics and Mathematical Systems, No. 186; Springer-Verlag: Berlin, Germany, 1981.

29. Chen, S.J.; Hwang, C.L. Fuzzy Multiple Attribute Decision Making; Lecture Notes in Economics and Mathematical Systems, No. 375; Springer-Verlag: Berlin, Germany, 1992.

30. Chen, C.-T. Extensions to the TOPSIS for group decision-making under fuzzy environment. Fuzzy Sets Syst. 2000, 114, 1-9.

31. Berger, P.A. Generating agricultural landscapes for alternative futures analysis: A multiple attribute decision-making model. Trans. GIS 2006, 10, 103-120.

32. Prato, T. Fuzzy adaptive management of social and ecological carrying capacities for protected areas. J. Environ. Manag. 2009, 90, 2551-2557.

33. Prato, T. Increasing resilience of natural protected areas to future climate change: A fuzzy adaptive management approach. Ecol. Model. 2012, 242, 46-53.

34. Holling, C.S. Adaptive Environmental Assessment and Management; John Wiley \& Sons: Chichester, UK, 1978.

35. Walters, C. Adaptive Management of Renewable Resources; Macmillan and Co.: New York, NY, USA, 1996.

36. Parma, A.M. NCEAS Working Group on Population Management. What can adaptive management do for our fish, forest, food, and biodiversity? Integr. Biol. 1998, 1, 16-26. 
37. Kohm, K.A.; Franklin, J.F. Introduction. In Creating Forestry for the 21st Century: The Science of Ecosystem Management; Kohm, K.A., Franklin, J.F., Eds.; Island Press: Washington, DC, USA, 1997; pp. 1-5.

38. National Research Council. Chapter 1: What is Adaptive Management? In Adaptive Management for Water Resources Planning; The National Academies Press: Washington, DC, USA, 2004; p. 4.

39. Williams, B.K. Passive and active adaptive management: Approaches and an example. J. Environ. Manag. 2011, 92, 1371-1378.

40. Nyberg, J.B. Statistics and the practice of adaptive management. In Statistical Methods for Adaptive Management Studies; Land Management Handbook No. 42; Sit, V., Taylor, B., Eds.; Ministry of Forests Research Program: Victoria, BC, Canada, 1998; pp. 1-8.

41. Prato, T. Adaptive management of national park ecosystems. Ecolog. Econ. 2006, 23, $72-86$.

42. Keane, R.E.; Cary, G.J.; Flannagan, M.D. Challenges and needs in fire management: A landscape simulation modeling perspective. In Landscape Ecology in Forest Management and Conservation: Challenges and Solutions for Global Change; Li, C., Lafortezza, R., Chen, J.J., Eds.; Springer, Higher Education Press: Beijing, China, 2011; pp. 75-98.

43. Hayes, S.W.; Keegan, C.E., III; Morgan, T.A. Estimating Harvesting Costs; Bureau of Business and Economic Research, University of Montana: Missoula, MT, USA, 2011. Available online: http://www.bber.umt.edu/pubs/forest/prices/loggingCostPoster2011.pdf (accessed on 23 March 2015).

44. Finney, M.A.; McHugh, C.W.; Grenfell, I.; Riley, K.L. Continental-scale simulation of burn probabilities, flame lengths, and fire size distribution for the United States. In Proceedings of the VI International Conference on Forest Fire Research, University of Coimbra, Coimbra, Portugal, 15-18 November 2010; Viegas, D.X., Ed.; p. 12.

45. Prato, T.; Paveglio, T.; Barnett, Y.; Silverstein, R.; Hardy, M.; Keane, R.; Loehman, R.; Clark, A.; Fagre, D.; Venn, T.; et al. Simulating future residential property losses from wildfire in Flathead County, Montana. In Advances in Environment Research; Daniels, J.A., Ed.; Hauppauge, Nova Science Publishers, Inc.: New York, NY, USA, 2014; Volume 33, pp. 1-40.

46. Keane, R.E.; Hessburg, P.F.; Landres, P.B.; Swanson, F.J. The use of historical range and variability (HRV) in landscape management. For. Ecol. Manag. 2009, 258, 1025-1037.

47. Aplet, G.; Keeton, W.S. Application of historical range of variability concepts to biodiversity conservation. In Practical Approaches to the Conservation of Biological Diversity; Baydack, R.K., Campa, H., Haufler, J.B., Eds.; Island Press: New York, NY, USA, 1999; pp. 71-86.

48. Prato, T. Multiple attribute evaluation of landscape management. J. Environ. Manag. 2000, 60, $325-337$.

49. Richardson, J.W.; Schumann, K.D.; Feldman, P.A. Simetar; Texas A\&M University: College Station, TX, USA, 2014. Available online: http://simetar.com/ (accessed on 23 March 2015).

(C) 2015 by the author; licensee MDPI, Basel, Switzerland. This article is an open access article distributed under the terms and conditions of the Creative Commons Attribution license (http://creativecommons.org/licenses/by/4.0/). 